\title{
ANCA-associated vasculitis after COVID-19
}

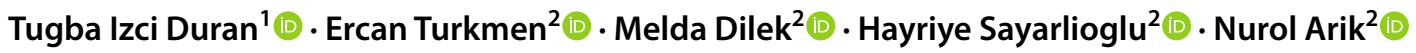

Received: 6 April 2021 / Accepted: 3 June 2021 / Published online: 7 June 2021

(c) The Author(s), under exclusive licence to Springer-Verlag GmbH Germany, part of Springer Nature 2021

\begin{abstract}
Antineutrophil cytoplasmic antibody (ANCA)-associated vasculitis (AAV) are systemic autoimmune diseases that may lead to renal failure due to the infiltration of mononuclear cells and the destruction of small- and medium-sized blood vessels. It has been shown that severe acute respiratory syndrome coronavirus 2 (SARS-CoV-2) may trigger the presentation or exacerbation of autoimmune diseases. Crescentic glomerulonephritis (GN) has rarely been reported in patients with Coronavirus disease-2019 (COVID-19). We present rare two cases with AAV after a recent diagnosis of COVID-19. The first case was 26-year-old male patient, who was presented with acute kidney injury after COVID-19. Serum creatinine increased and active urine sediment was seen. Serological evaluation showed anti-myeloperoxidase antibody was at a level of $80.6 \mathrm{U} / \mathrm{mL}$. Kidney biopsy showed necrotizing GN with cellular crescents. Methylprednisolone, cyclophosphamide and plasma exchange were administered. He was discharged with hemodialysis. Second case was a 36-year-old female who was hospitalized because of fever, cough and dyspnea. After she was diagnosed with COVID-19, she had total hearing loss, with cavitary lesions on bilateral lung parenchyma and an acute kidney injury. Serological evaluation showed an elevated antiproteinase-3 with a level of 1:32. Kidney biopsy showed necrotizing GN with cellular crescents. Renal function improved after methylprednisolone and cyclophosphamide treatment. With a systematic review of the literature, we found four cases of new-onset AAV due to COVID-19. Herein, we discuss two cases and provide a literature review on cases of new-onset pauci-immune GN after COVID-19 infection.
\end{abstract}

Keywords Anti-neutrophil cytoplasmic antibody-associated vasculitis/diagnosis* . COVID-19 · Glomerulonephritis/ pathology* SARS-CoV-2*

\section{Introduction}

Tugba Izci Duran

drtugbaizciduran@gmail.com

Ercan Turkmen

ercan.turkmen1907@gmail.com

Melda Dilek

dilekmelda@yahoo.com

Hayriye Sayarlioglu

hayriyesayarlioglu@yahoo.com

Nurol Arik

nurarik@superonline.com

1 Division of Rheumatology, Department of Internal Medicine, Ondokuz Mayis University Medical Faculty, Korfez Mahallesi, 55270 Atakum/Samsun, Turkey

2 Division of Nephrology, Department of Internal Medicine, Ondokuz Mayis University Medical Faculty, Korfez Mahallesi, 55270 Atakum/Samsun, Turkey
Antineutrophil cytoplasmic autoantibody (ANCA)-associated vasculitis (AAV) is a disorder that affects predominantly small- and medium-sized arteries and has similar features on kidney histology [e.g., a focal necrotizing, often crescentic, pauci-immune glomerulonephritis (GN)] [1]. The events leading to the initiation of AAV are not well understood. Some factors are involved in the pathogenesis of the disease by triggering autoimmunity due to genetic factors, infectious agents, various specific drugs, environmental exposures and other factors [2-5]. Coronavirus disease-19 (COVID-19), a newly occurred respiratory disease caused by severe acute respiratory syndrome coronavirus-2 (SARS-CoV-2), was first detected in China, in December 2019, and has caused deaths of more than 2.5 million people thus far. As the COVID-19 outbreak continues to expand, many aspects of this disease are being defined and described in detail. Acute kidney injury (AKI) has also been 
very common during the course of COVID-19. In a study conducted in the United States, Hirsch et al. reported that the incidence of AKI was $36.6 \%$ in patients hospitalized with COVID-19 [6]. AKI is common among critically ill patients with COVID-19 and has been emphasized as an independent mortality indicator [7]. Previous studies have reported that different mechanisms are responsible for AKI in COVID-19 patients [8-12]. It has been shown in the pathophysiology of COVID-19 that it may lead to the emergence or exacerbation of autoimmune diseases in genetically susceptible patients $[13,14]$. Although cases of kidney damage due to COVID19 have been reported, an association between COVID-19 and crescentic GN has been rarely identified. To date, only four cases of AAV with COVID-19 have been reported [15-17]. Herein, we aimed to discuss 2 cases and provide a literature review on cases of new-onset pauci-immune GN after COVID-19 who clinically improved with immunosuppressants therapy and review the previous studies including similar cases.

\section{Case presentation}

\section{Case 1}

A 26-year-old male patient was admitted to the outpatient clinic with fever, fatigue, and cough. Upon detection of subpleural and parenchymal dispersed consolidative ground-glass opacities (GGOs) in the bilateral lung parenchyma on the thoracic computed tomography (CT), favipiravir treatment was given with the diagnosis of COVID-19. Although, the patient had normal basal serum creatinine $(\mathrm{sCr})$ level $(0.8 \mathrm{mg} / \mathrm{dL})$; oliguria and renal dysfunction was detected (with sCr level of $6.03 \mathrm{mg}$ / dL) during follow-up. While the kidney size and parenchymal echogenicity were normal on renal ultrasonography
(USG), urinalysis revealed an active sediment with dysmorphic erythrocytes and significant proteinuria. Antimyeloperoxidase antibody [MPO, perinuclear-antineutrophilic autoantibody (p-ANCA)] was determined to be $3+$ and anti-proteinase 3 [PR3 cytoplasmic-antineutrophilic autoantibody (c-ANCA)] to be $1+$. Repeated serologies revealed a high p-ANCA titer $(1: 100)$ with a specific MPO titer level of $80.6 \mathrm{U} / \mathrm{mL}$, positive antinuclear antibody (1:100, granular pattern), negative anti-double strand DNA antibody (anti-dsDNA), negative anti-glomerular basement membrane antibody, and normal serum complements. A kidney biopsy was performed and pauci-immune, crescentic GN with minimal glomerular and interstitial fibrosis and tubular atrophy was seen in biopsy. Hence, the clinicopathological diagnosis was pauci-immune crescentic GN, in the setting of MPO-AAV. Intermittent hemodialysis treatment was initiated and pulse methylprednisolone therapy ( $1 \mathrm{~g}$ intravenous (IV) 3 days) was administered. During the follow-up, the patient had fever and procalcitonin: 1.41 , CRP: $79 \mathrm{mg} / \mathrm{dL}$ were detected. Thus, meropenem and teicoplanin were administered due to catheter infection. On the thoracic CT, diffuse acinar opacities, GGOs, and septal thickenings were observed in both lungs but were more prominent in the central perihilar areas. The appearance was primarily interpreted as an alveolar hemorrhage. The patient received pulse methylprednisolone therapy ( $1 \mathrm{~g}$ IV 3 days), as well as plasma exchange 10 times. After infection treatment, the patient was administered cyclophosphamide $(500 \mathrm{mg} \mathrm{IV}$ two doses at 15-day intervals) during the hospitalization. Subsequently, oral prednisone treatment was administered. After two doses of cyclophosphamide, mechanical ventilation was not required and the lung findings regressed. However, hemodialysis was continued and he was scheduled to receive cyclophosphamide (1 g IV once a month for four doses) (Fig. 1).

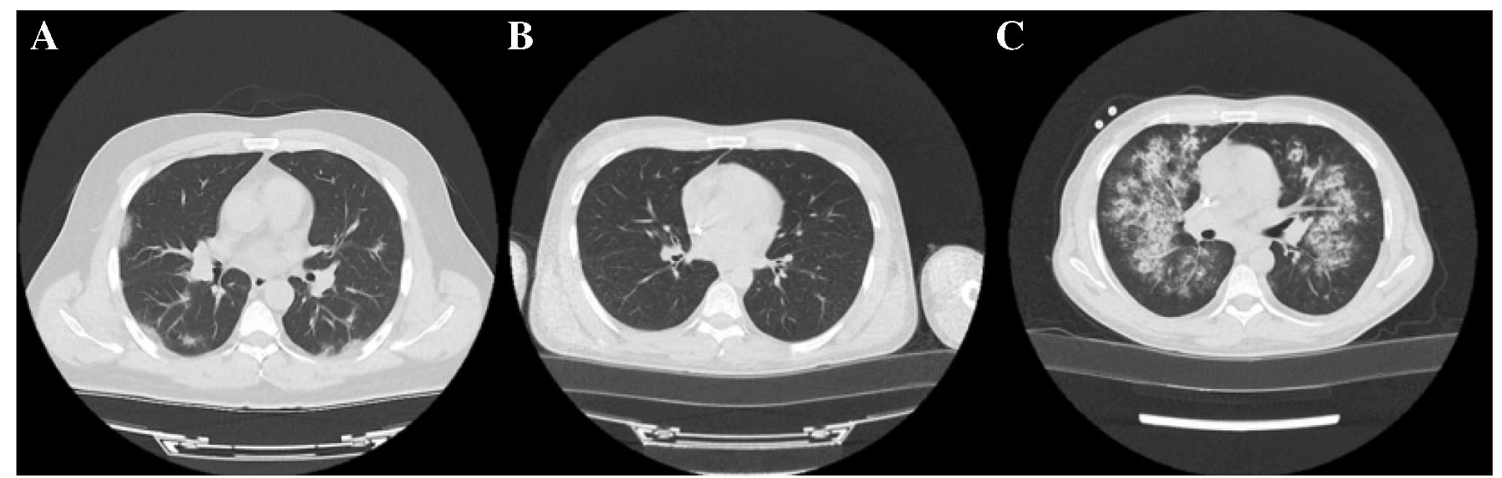

Fig. 1 Thoracic computed tomography images of Case 1. A Diagnosis of COVID-19 was established based upon peripheral and mainly posteriorly located GGOs. B After favipiravir treatment, lung findings such as GGOs regressed. C On the thoracic CT after the patient had cough and dyspnea again, diffuse acinar alveolar opacities and GGOs were observed in both lungs, which were more prominent in the central perihilar areas 


\section{Case 2}

A 36-year-old female patient was hospitalized with fever, cough and dyspnea. A few weeks before, the SARS-CoV-2 polymerase chain reaction (PCR) was positive on nasopharyngeal swab. She received favipiravir for 5 days. After COVID-19, she had total hearing loss, with cavitary lesions on bilateral lung parenchyma, and an AKI with a $\mathrm{sCr}$ level of $1.35 \mathrm{mg} / \mathrm{dL}$ on admission. Urinalysis revealed an active sediment with dysmorphic erythrocytes and significant proteinuria, and her serum albumin level was low, at $2.47 \mathrm{~g} /$ dL. Renal function gradually deteriorated and peak $\mathrm{sCr}$ level of $1.91 \mathrm{mg} / \mathrm{dL}$. In the microbiological assessment for cavitary lesions, tuberculosis PCR and galactomannan antigen were negative. Serological evaluation showed negative antinuclear antibody, and anti-dsDNA, normal serum complements, and an elevated PR3 1:32. In kidney biopsy, pauci-immune necrotizing GN with cellular crescents was detected. The patient received pulse dose corticosteroids (methylprednisolone IV at a dose of $250 \mathrm{mg}$ daily for 3 days) and subsequently, she was transitioned to oral prednisone. She received cyclophosphamide $(0.5 \mathrm{~g}$ IV two doses at 15-day intervals) during the hospitalization. While hematuria and proteinuria were not detected in the most recent urinalysis, the $\mathrm{sCr}$ level decreased to $1.41 \mathrm{mg} / \mathrm{dL}$. She was scheduled to receive cyclophosphamide ( $0.5 \mathrm{~g}$ IV 15 days interval for eight doses). Total hearing loss continued, so she was referred to otorhinolaryngology for cochlear implant (Fig. 2).

\section{Search strategy and literature overview}

According to the guidance on narrative biomedical review [18], the authors conducted a literature search from December 2019 to November 1, 2020, in Scopus and PubMed up to May 10th, 2021, combining the MeSH search terms ("Severe Acute Respiratory Syndrome Coronavirus 2" OR "Coronavirus" OR "COVID-19" AND "Anti-Neutrophil Cytoplasmic
Antibody-Associated Vasculitis"). Clinical studies, case reports, and case series reporting ANCA-associated vasculitis after COVID-19 published in English were included. Two authors (TID, ET) independently screened titles, abstracts, and full texts of all relevant articles. The search results were reviewed by the two authors and the articles included were agreed upon. From each article selected, data were collected on publication year, age, gender, comorbidities, clinical features, laboratory tests, serological profile, kidney pathology, antiviral therapy, renal replacement therapy, AAV therapy, complications and outcome. Non-English articles were not evaluated for this review.

\section{Discussion}

Since COVID-19 first emerged in December 2019, approximately $20 \%$ of the cases have been severe disease that has presented with various clinical manifestations [19]. Differential diagnosis of the other infectious and inflammatory diseases during diagnostic procedures of these critical patients is very critical. During the COVID-19 pandemic, the diagnosis and treatment of AAV have been discussed in many ways. AAV can mimic COVID-19 in terms of pulmonary involvement, COVID-19 may occur simultaneously with AAV, and COVID-19 can cause AAV-like symptoms [20-23]. Therefore, it has forced the clinicians to be more careful. The diagnosis of new-onset AAV can be challenging in COVID-19 patients because some of the symptoms and clinical manifestations of both diseases are common.

Pulmonary involvement is very common in both AAV and COVID-19. In COVID-19, peripherally and posteriorly distributed multifocal bilateral GGOs and consequent overlapping of the consolidations are considered as the dominant radiological appearance of the disease and this may be accompanied by pleural effusion and cavitation [24]. In AAV, primary pulmonary involvement due to alveolar hemorrhage resembles nonspecific interstitial pneumonia or
Fig. 2 Thoracic computed tomography images of Case 2, before and after immunosuppressive therapy. A Thoracic CT taken a couple of weeks after the confirmation of COVID-19 infection, on which the bilateral pleural effusion and perihilar cavitation can be observed. B Regression of pleural effusion and GGOs during the first week of immunosuppressive treatment given after the diagnosis of AAV

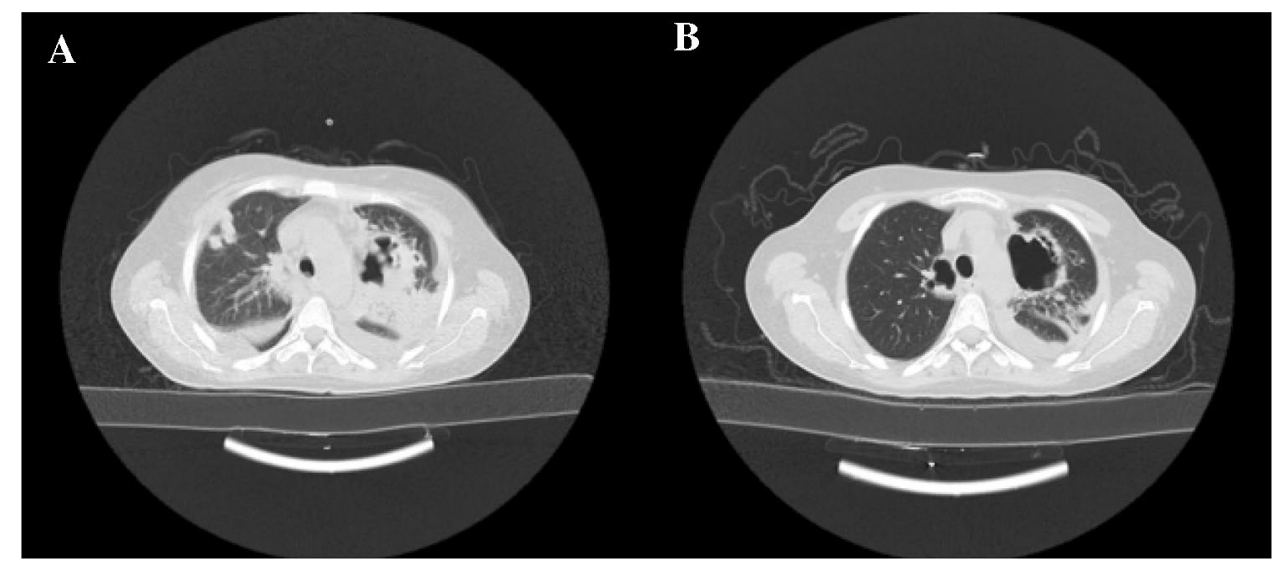


patchy ground-glass appearance, but the involvement sometimes can be confusing. Therefore, it is recommended to use serological tests and clinical data to distinguish SARS$\mathrm{CoV}-2$ infection from the underlying autoimmune lung disease [23].

With the present report, we identified 3 reports describing cases of AAV after COVID-19 and the table includes an update of the published cases written in English [15-17] (Table 1). In the literature, a total of four different cases of AAV developed after COVID-19 have been reported, including one from Iran and three from the USA [15-17]. A total of six cases were included in this review. Of the six patients (including ours), four (66.6\%) were men with a mean age of $40.5 \pm 14.7$. There was one case $(16.6 \%)$ diagnosed with systemic sclerosis prior to COVID-19 [17]. Immunological tests showed positive p-ANCA in three cases (the present report (PR) and [15, 17]) and positive c-ANCA in three cases $([15,16]$ and PR). Imaging studies showed patchy GGOs in five cases
$([15,17]$ and PR), bilateral pleural effusion in two cases ([17] and PR), alveolar hemorrhage in one case [16], and bilateral cavitary lesions in one case (PR). Treatment for COVID-19 was administered in five patients, favipiravir in one case (PR), tocilizumab and convalescent plasma in one case [15], and hydroxychloroquine in two cases $[15,16]$. And also, AAV was treated with glucocorticoids in all cases; cyclophosphamide was administered in three patients ([16] and PR]; rituximab in two patients [15]; plasmapheresis [16] in one patient and plasma exchange in one patient (PR). Two patients required supplemental oxygen ([15] and PR). While all patients had active urinary sediment and high creatinine levels, two patients had kidney failure that required hemodialysis ([15] and PR). Renal biopsy was performed in all six patients and crescentic GN was detected in all cases ([15-17] and PR).

In addition to pulmonary involvement, the development of signs of other systemic involvement, such as AKI, may be guiding in these patients to AAV; however, a high rate

Table 1 The summary of the clinical and demographic findings, and treatment strategies of these two cases and the previously published cases of AAV with COVID-19

\begin{tabular}{|c|c|c|c|c|c|c|}
\hline Case no. & 1 & 2 & Uppal et al. [15] & Uppal et al. [15] & $\begin{array}{l}\text { Moeinzadeh et al. } \\
\text { [16] }\end{array}$ & $\begin{array}{l}\text { Jalalzadeh et al. } \\
\text { [17] }\end{array}$ \\
\hline Age, years & 26 & 36 & 64 & 46 & 25 & 46 \\
\hline Sex & Male & Female & Male & Male & Male & Female \\
\hline Comorbidities & None & None & None & Diabetes mellitus & None & $\begin{array}{l}\text { Diabetes mellitus } \\
\text { and scleroderma }\end{array}$ \\
\hline Peak SCr (mg/dL) & 8.44 & 1.91 & 7.87 & 4.0 & 5.5 & 8.3 \\
\hline $\begin{array}{l}\text { Serum albumin, } \\
(\mathrm{g} / \mathrm{dL})\end{array}$ & 2.58 & 2.22 & 2.8 & 2.1 & NA & NA \\
\hline Positive serology & MPO (p-ANCA) & PR3 (c-ANCA) & MPO (p-ANCA) & PR3 (c-ANCA) & PR3 (c-ANCA) & MPO (p-ANCA) \\
\hline Lung involvement & $\begin{array}{l}\text { Subpleural and } \\
\text { parenchymal dis- } \\
\text { persed consolida- } \\
\text { tive ground-glass } \\
\text { opacities }\end{array}$ & $\begin{array}{l}\text { Bilateral cavitary } \\
\text { lesions }\end{array}$ & $\begin{array}{l}\text { Bilateral patchy } \\
\text { infiltrates }\end{array}$ & $\begin{array}{l}\text { Resolving periph- } \\
\text { eral ground-glass } \\
\text { opacities }\end{array}$ & $\begin{array}{l}\text { Alveolar hemor- } \\
\text { rhage }\end{array}$ & $\begin{array}{l}\text { Bilateral pleural } \\
\text { effusions and } \\
\text { pulmonary } \\
\text { infiltrates }\end{array}$ \\
\hline Skin pathology & None & None & None & $\begin{array}{l}\text { Leukocytoclastic } \\
\text { vasculitis }\end{array}$ & None & None \\
\hline Kidney pathology & Crescentic GN & $\begin{array}{l}\text { Necrotizing cres- } \\
\text { centic GN }\end{array}$ & Crescentic GN & $\begin{array}{l}\text { Focal necrotizing } \\
\text { GN }\end{array}$ & Crescentic GN & Crescentic GN \\
\hline $\begin{array}{l}\text { Renal replacement } \\
\text { therapy }\end{array}$ & Yes, hemodialysis & No & Yes, hemodialysis & No & No & No \\
\hline $\begin{array}{l}\text { COVID-19 treat- } \\
\text { ment }\end{array}$ & Favipiravir & Favipiravir & $\begin{array}{l}\text { Tocilizumab, } \\
\text { convalescent } \\
\text { plasma }\end{array}$ & $\begin{array}{l}\text { Hydroxychloro- } \\
\text { quine, azithro- } \\
\text { mycin }\end{array}$ & $\begin{array}{l}\text { Hydroxychloro- } \\
\text { quine, levofloxa- } \\
\text { cin, IVIG }\end{array}$ & NA \\
\hline AAV treatment & $\begin{array}{l}\text { Glucocorticoids, } \\
\text { cyclophospha- } \\
\text { mide, plasma } \\
\text { exchange }\end{array}$ & $\begin{array}{l}\text { Glucocorticoids, } \\
\text { cyclophospha- } \\
\text { mide }\end{array}$ & $\begin{array}{l}\text { Glucocorticoids, } \\
\text { rituximab }\end{array}$ & $\begin{array}{l}\text { Glucocorticoids, } \\
\text { rituximab }\end{array}$ & $\begin{array}{l}\text { Glucocorticoids, } \\
\text { cyclophospha- } \\
\text { mide, plasma- } \\
\text { pheresis }\end{array}$ & Glucocorticoids \\
\hline $\begin{array}{l}\text { Antibody titers on } \\
\text { admission }\end{array}$ & MPO: $80.6 \mathrm{U} / \mathrm{mL}$ & c-ANCA (1:32) & MPO: $32.5 \mathrm{U} / \mathrm{mL}$ & PR-3: $57.3 \mathrm{U} / \mathrm{mL}$ & c-ANCA (1:50) & p-ANCA $>1: 1280$ \\
\hline
\end{tabular}

c-ANCA, cytoplasmic antineutrophilic autoantibody; COVID-19, coronavirus disease 2019; GN, glomerulonephritis; IVIG; intravenous immunoglobulin; p-ANCA, perinuclear antineutrophilic autoantibody; MPO, myeloperoxidase; NA, not available; PR3, proteinase 3; sCr, serum creatinine 
of AKI, reaching up to 50\% [25], in hospitalized patients during SARS-CoV-2 infection reduces the effect of this contribution. Hence, urine sediment should be carefully evaluated. Causes of SARS-CoV-2-induced AKI may vary from pre-renal azotemia to acute tubular injury requiring renal replacement therapy with a pathophysiology of TMA, vasculitis, and collapsing glomerulopathy [8-10, 12]. AAV has a preference for the kidney, and $>75 \%$ of patients have renal involvement characterized by rapidly progressive GN [26]. The typical renal appearance is a rapidly progressive GN with a decrease in renal function accompanied by hypertension, microscopic hematuria, and subnephrotic range proteinuria over days to a few months. Due to these shared features that can be detected in both COVID-19 and AAV, it may be difficult to distinguish the etiology of AKI that occurs during or after COVID-19. There was kidney disease in both present cases. While renal involvement was severe in the first case, lung involvement was prominent in the second case. Therefore, this should be considered seriously when making the differential diagnosis.

The fact that SARS-CoV-2 infection can be a 'trigger factor' for vasculitis is an interesting topic in the debate between COVID-19 and AAV. SARS-CoV-2 infection may trigger autoimmunity and autoimmune diseases [14, 27]. It has been reported in previous studies that systemic viral and/or bacterial infections may trigger autoimmunity and cause granulomatous polyangiitis (GPA) [3, 4]. Somer et al. reported cases of parvovirus-19 and cytomegalovirusinduced GPA [3]. Kallenberg et al. reported that the superantigens of staphylococcus aureus may be involved in first phase of GPA by activating a limited polyclonal response, possibly involving a specific autoimmune response [4].

The mechanisms that may trigger autoimmunity following SARS-CoV-2 infection include bystander killing, molecular mimicry, viral persistence, epitope spreading, and formation of neutrophil extracellular traps (NETs) [28, 29]. Patients with AAV also have high levels of circulating NETs and NETs have been observed in the kidney biopsy specimens of patients with AAV [30]. NETs contain proinflammatory proteins and are thought to contribute to the development of vasculitis directly by causing endothelial cell injury, and activating the complement system and indirectly by the production of PR3 and MPO-ANCA. It should be noted that if NETs are exposed to proteins for a long period of time due to overproduction and/or there is reduced clearance of NETs, this may be important in AAV [31]. Thus, this highlights the ability of SARS-CoV-2 to trigger autoimmunity phenomenon, which can cause to onset or flare-up of AAV.

The limited number and the retrospective evaluation of the cases are the limitations of this review. Additionally, the pathophysiology of COVID-19 is still not fully elucidated and continues to be investigated. The spectrum of symptoms that can cause in patients with a previous or new onset of AAV is still unknown. Thus, this case-based review can provide useful information regarding the assessment of the clinical symptoms, methods of diagnosis, and management of this confusing condition.

In conclusion, the diagnosis of flare or newly onset of AAV in a patient with COVID-19 is a challenge. When the cases in the literature are evaluated, the clinical keys that can help for the differential diagnosis are kidney damage, which occurs regardless of the severity of pulmonary involvement. The development of manifestations of vasculitis following regression of the initial pulmonary involvement due to COVID-19 in the first case herein can be striking from this aspect. It suggests that this connection may be strong and SARS-CoV-2 infection may be a trigger for vasculitis. The presence of such findings should lead to the determination of immunological markers to assess or rule out the AAV. The aim should be to quickly diagnose and specific treatment can be initiated in a timely manner AAV so that it does not cause permanent organ damage.

\section{Take-home messages}

- SARS-CoV-2 infection can be a 'trigger factor' for vasculitis.

- ANCA-associated vasculitis should be kept in mind in patients who develop acute kidney injury after COVID19.

Author contributions TID: writing of manuscript including editing and revision and the literature review at all stages of its production. ET: writing of manuscript including editing and revision and the literature review at all stages of its production, and clinical management of patients. MD: manuscript editing and revision at all stages of production, final approval of manuscript and clinical management of patients. HS: manuscript editing and revision at all stages of production, final approval of manuscript, and clinical management of patients. NA: manuscript editing and revision at all stages of production, final approval of manuscript, and clinical management of patients.

Funding The authors received no financial support for the research and/or authorship of this article.

\section{Declarations}

Conflict of interest All the authors declare no conflict of interest.

Ethical approval All procedures performed in studies involving human participants were in accordance with the ethical standards of the institutional and/or national research committee and with the 1964 Helsinki declaration and its later amendments or comparable ethical standards. 
Informed consent Written informed consent was obtained from the patient for the publication of this case-based review, in compliance with the COPE best practice guidelines.

\section{References}

1. Jennette JC, Falk RJ, Bacon PA, Basu N, Cid MC, Ferrario F, Flores-Suarez LF, Gross WL, Guillevin L, Hagen EC, Hoffman GS, Jayne DR, Kallenberg CG, Lamprecht P, Langford CA, Luqmani RA, Mahr AD, Matteson EL, Merkel PA, Ozen S, Pusey CD, Rasmussen N, Rees AJ, Scott DG, Specks U, Stone JH, Takahashi K, Watts RA (2013) 2012 Revised international chapel hill consensus conference nomenclature of vasculitides. Arthritis Rheum 65(1):1-11. https://doi.org/10.1002/art.37715

2. Gómez-Puerta JA, Gedmintas L, Costenbader KH (2013) The association between silica exposure and development of ANCAassociated vasculitis: systematic review and meta-analysis. Autoimmun Rev 12(12):1129-1135. https://doi.org/10.1016/j.autrev. 2013.06.016

3. Somer T, Finegold SM (1995) Vasculitides associated with infections, immunization, and antimicrobial drugs. Clin Infect Dis 20(4):1010-1036. https://doi.org/10.1093/clinids/20.4.1010

4. Kallenberg CG (2004) The role of bacterial infections for the initiation and exacerbation of systemic vasculitis. Autoimmun Rev 3(Suppl 1):S45-47

5. Peschel A, Basu N, Benharkou A, Brandes R, Brown M, Rees AJ, Kain R (2014) Autoantibodies to hLAMP-2 in ANCA-negative pauci-immune focal necrotizing GN. J Am Soc Nephrol 25(3):455-463. https://doi.org/10.1681/asn.2013030320

6. Hirsch JS, Ng JH, Ross DW, Sharma P, Shah HH, Barnett RL, Hazzan AD, Fishbane S, Jhaveri KD (2020) Acute kidney injury in patients hospitalized with COVID-19. Kidney Int 98(1):209218. https://doi.org/10.1016/j.kint.2020.05.006

7. Ronco C, Reis T, Husain-Syed F (2020) Management of acute kidney injury in patients with COVID-19. Lancet Respir Med 8(7):738-742. https://doi.org/10.1016/s2213-2600(20)30229-0

8. Nasr SH, Kopp JB (2020) COVID-19-associated collapsing glomerulopathy: an emerging entity. Kidney Int Rep 5(6):759-761. https://doi.org/10.1016/j.ekir.2020.04.030

9. Su H, Yang M, Wan C, Yi LX, Tang F, Zhu HY, Yi F, Yang HC, Fogo AB, Nie X, Zhang C (2020) Renal histopathological analysis of 26 postmortem findings of patients with COVID-19 in China. Kidney Int 98(1):219-227. https://doi.org/10.1016/j.kint.2020.04. 003

10. Gaillard F, Ismael S, Sannier A, Tarhini H, Volpe T, Greze C, Verpont MC, Zouhry I, Rioux C, Lescure FX, Buob D, Daugas E (2020) Tubuloreticular inclusions in COVID-19-related collapsing glomerulopathy. Kidney Int 98(1):241. https://doi.org/10.1016/j. kint.2020.04.022

11. Jhaveri KD, Meir LR, Flores Chang BS, Parikh R, Wanchoo R, Barilla-LaBarca ML, Bijol V, Hajizadeh N (2020) Thrombotic microangiopathy in a patient with COVID-19. Kidney Int 98(2):509-512. https://doi.org/10.1016/j.kint.2020.05.025

12. Mohamed MM, Lukitsch I, Torres-Ortiz AE, Walker JB, Varghese V, Hernandez-Arroyo CF, Alqudsi M, LeDoux JR, Velez JCQ (2020) Acute kidney injury associated with coronavirus disease 2019 in urban New Orleans. Kidney. https://doi.org/10.3467/KID. 0002652020

13. Caso F, Costa L, Ruscitti P, Navarini L, Del Puente A, Giacomelli R, Scarpa R (2020) Could Sars-coronavirus-2 trigger autoimmune and/or autoinflammatory mechanisms in genetically predisposed subjects? Autoimmun Rev 19(5):102524. https://doi.org/10. 1016/j.autrev.2020.102524
14. Gracia-Ramos AE, Saavedra-Salinas MÁ (2021) Can the SARS$\mathrm{CoV}-2$ infection trigger systemic lupus erythematosus? A casebased review. Rheumatol Int 41(4):799-809. https://doi.org/10. 1007/s00296-021-04794-7

15. Uppal NN, Kello N, Shah HH, Khanin Y, De Oleo IR, Epstein E, Sharma P, Larsen CP, Bijol V, Jhaveri KD (2020) De novo ANCA-associated vasculitis with glomerulonephritis in COVID19. Kidney Int Rep 5(11):2079-2083. https://doi.org/10.1016/j. ekir.2020.08.012

16. Moeinzadeh F, Dezfouli M, Naimi A, Shahidi S, Moradi H (2020) Newly diagnosed glomerulonephritis during COVID-19 infection undergoing immunosuppression therapy, a case report. Iran J Kidney Dis 14(3):239-242

17. Jalalzadeh M, Valencia-Manrique JC, Boma N, Chaudhari A, Chaudhari S (2021) Antineutrophil cytoplasmic antibody-associated glomerulonephritis in a case of scleroderma after recent diagnosis with COVID-19. Cureus 13(1):e12485-e12485. https:// doi.org/10.7759/cureus.12485

18. Gasparyan AY, Ayvazyan L, Blackmore H, Kitas GD (2011) Writing a narrative biomedical review: considerations for authors, peer reviewers, and editors. Rheumatol Int 31(11):1409-1417. https:// doi.org/10.1007/s00296-011-1999-3

19. Guan WJ, Ni ZY, Hu Y, Liang WH, Ou CQ, He JX, Liu L, Shan H, Lei CL, Hui DSC, Du B, Li LJ, Zeng G, Yuen KY, Chen RC, Tang CL, Wang T, Chen PY, Xiang J, Li SY, Wang JL, Liang ZJ, Peng YX, Wei L, Liu Y, Hu YH, Peng P, Wang JM, Liu JY, Chen Z, Li G, Zheng ZJ, Qiu SQ, Luo J, Ye CJ, Zhu SY, Zhong NS (2020) Clinical characteristics of Coronavirus disease 2019 in China. N Engl J Med 382(18):1708-1720. https://doi.org/10. 1056/NEJMoa2002032

20. Hashizume H, Sano Y, Furukawa S, Imokawa S (2020) Eosinophilic granulomatosis with polyangiitis mimicking coronavirus disease 2019: a case report. J Eur Acad Dermatol Venereol 34(10):e557-e559. https://doi.org/10.1111/jdv.16705

21. Qurratulain Q, Ahmed A, Jones Q (2021) Lesson of the month: severe granulomatosis with polyangiitis (GPA): a diagnostic challenge during the COVID-19 pandemic. Clin Med (Lond) 21(1):79-80. https://doi.org/10.7861/clinmed.2020-0793

22. Becker RC (2020) COVID-19-associated vasculitis and vasculopathy. J Thromb Thrombolysis 50(3):499-511. https://doi.org/ 10.1007/s11239-020-02230-4

23. Eslambolchi A, Aghaghazvini L, Gholamrezanezhad A, Kavosi H, Radmard AR (2021) Coronavirus disease 2019 (COVID-19) in patients with systemic autoimmune diseases or vasculitis: radiologic presentation. J Thromb Thrombolysis 51(2):339-348. https://doi.org/10.1007/s11239-020-02289-z

24. Martínez Chamorro E, Díez Tascón A, Ibáñez Sanz L, Ossaba Vélez S, Borruel Nacenta S (2021) Radiologic diagnosis of patients with COVID-19. Radiologia 63(1):56-73. https://doi. org/10.1016/j.rx.2020.11.001

25. Chan L, Chaudhary K, Saha A, Chauhan K, Vaid A, Zhao S, Paranjpe I, Somani S, Richter F, Miotto R, Lala A, Kia A, Timsina P, Li L, Freeman R, Chen R, Narula J, Just AC, Horowitz C, Fayad Z, Cordon-Cardo C, Schadt E, Levin MA, Reich DL, Fuster V, Murphy B, He JC, Charney AW, Böttinger EP, Glicksberg BS, Coca SG, Nadkarni GN (2021) AKI in hospitalized patients with COVID-19. J Am Soc Nephrol 32(1):151-160. https://doi.org/10. 1681/asn.2020050615

26. Geetha D, Jefferson JA (2020) ANCA-associated vasculitis: core curriculum 2020. Am J Kidney Dis 75(1):124-137. https://doi. org/10.1053/j.ajkd.2019.04.031

27. Zhou Y, Han T, Chen J, Hou C, Hua L, He S, Guo Y, Zhang S, Wang Y, Yuan J, Zhao C, Zhang J, Jia Q, Zuo X, Li J, Wang L, Cao Q, Jia E (2020) Clinical and autoimmune characteristics of severe and critical cases of COVID-19. Clin Transl Sci 13(6):1077-1086. https://doi.org/10.1111/cts.12805 
28. Shah S, Danda D, Kavadichanda C, Das S, Adarsh MB, Negi VS (2020) Autoimmune and rheumatic musculoskeletal diseases as a consequence of SARS-CoV-2 infection and its treatment. Rheumatol Int 40(10):1539-1554. https://doi.org/10.1007/ s00296-020-04639-9

29. Puelles VG, Lütgehetmann M, Lindenmeyer MT, Sperhake JP, Wong MN, Allweiss L, Chilla S, Heinemann A, Wanner N, Liu S, Braun F, Lu S, Pfefferle S, Schröder AS, Edler C, Gross O, Glatzel M, Wichmann D, Wiech T, Kluge S, Pueschel K, Aepfelbacher M, Huber TB (2020) Multiorgan and renal tropism of SARS-CoV-2. N Engl J Med 383(6):590-592. https://doi.org/10.1056/NEJMc 2011400

30. Sharma P, Uppal NN, Wanchoo R, Shah HH, Yang Y, Parikh R, Khanin Y, Madireddy V, Larsen CP, Jhaveri KD, Bijol V (2020)
COVID-19-associated kidney injury: a case series of kidney biopsy findings. J Am Soc Nephrol 31(9):1948-1958. https://doi. org/10.1681/asn.2020050699

31. Söderberg D, Segelmark M (2016) Neutrophil extracellular traps in ANCA-associated vasculitis. Front Immunol 7:256-256. https://doi.org/10.3389/fimmu.2016.00256

Publisher's Note Springer Nature remains neutral with regard to jurisdictional claims in published maps and institutional affiliations. 